\title{
Edge Detection Versus Densitometry for Assessing Coronary Stenting Quantitatively
}

\author{
Bradley H. Strauss, MD, Yves Juilliere, MD, Benno J. Rensing, MD, \\ Johan H. C. Reiber, PhD, and Patrick W. Serruys, MD, PhD
}

The optimal method used to analyze quantitatively the immediate angiographic results of coronary stenting in the coronary arteries has not been studied. Accordingly, minimal luminal cross-sectional area was determined by 2 methods, edge detection and densitometry, in 19 patients who underwent percutaneous transhuminal coronary angioplasty (PTCA) and then coronary stent implantation for symptomatic coronary stenoses. The correlation coefficient, 0.73 before angioplasty, decreased to 0.59 after coronary angioplasty and then increased to $\mathbf{0 . 8 3}$ after stent implantation. The mean differences between edge detection and densitometric determinations of minimal luminal cross-sectional area were $0.31 \pm 0.51 \mathrm{~mm}^{2}$ before PTCA, -0.38 $\pm 1.22 \mathrm{~mm}^{2}$ after angioplasty and $0.35 \pm 0.79$ $\mathrm{mm}^{2}$ after coronary stenting. It is concluded that, although the correlation and variability in the measurement of minimal luminal cross-sectional area between edge detection and densitometry deteriorate after PTCA, they are improved after stenting, probably because of smoothing of the vessel contours by the stent and remodeling of the stented segment into a more circular configuration. Therefore, in the stented coronary artery, edge detection and densitometry are equally acceptable methods of analysis.

(Am J Cardiol 1991:67:484-490)
0 tenting of the coronary arteries is currently being investigated as an adjunct to percutaneous transluminal coronary angioplasty (PTCA). ${ }^{1}$ The optimal method used to analyze the immediate angiographic results of stenting in the coronary arteries has not yet been determined and is part of a general and unsettled controversy in the immediate assessment of PTCA Computer-based automatic edge detection angiographic analysis systems have reduced the variability resulting from visual and caliper-determined contour detection, ${ }^{2-4}$ but their use may be limited in eccentric lesions, particularly after angioplasty, when acute tears and dissections additionally distort the anatomy. Densitometry has been proposed as an alternative method of angiographic assessment of the severity of coronary obstructions because it is independent of the geometric shape..$^{5,6}$

The hemodynamic significance of a lesion has previously been shown to be most closely correlated with the minimal cross-sectional area. ${ }^{7,8}$ The determination of this parameter from edge detection programs from a single projection requires an assumption, often incorrect, that the vessel cross section is circular. ${ }^{9,10}$ Our group has previously shown that discrepancies exist in the postangioplasty analysis between edge detection and videodensitometric methods, although conflicting data have also been published. ${ }^{5,11,12}$ However, the situation after stenting of the coronary arteries may be altered, because the arterial wall typically assumes a smoother, more circular appearance. We therefore undertook this study to determine if stenting of coronary arteries after PTCA improves the correlation and agreement between videodensitometry and edge detection methods.

\section{METHODS}

Study patients: Nineteen patients, 13 men and 6 women, ranging in age from 41 to 70 years (mean 56), were enrolled after giving informed consent for stent implantation. The dilated and stented coronary artery was the left anterior descending coronary artery in 12 patients, the circumflex coronary artery in 2 , the right coronary artery in 3 and a coronary artery bypass vein graft in 2 . This series consisted of the first 19 patients in whom edge detection and videodensitometry were used to evaluate the immediate results of the procedure. In each patient, the coronary artery stenosis was dilated first. After successful angioplasty, the balloon catheter was exchanged for the stent delivery system over a 0.014-inch exchange guidewire. Unconstrained stents of 15 or $20 \mathrm{~mm}$ in length, depending on the lesion, were 


\begin{tabular}{|c|c|c|c|c|c|c|}
\hline \multirow[b]{2}{*}{ Pt. No. } & \multirow[b]{2}{*}{$\begin{array}{l}\text { Age }(y r) \\
\& \text { Sex }\end{array}$} & \multirow[b]{2}{*}{$\begin{array}{l}\text { PTCA } \\
\text { Vessel }\end{array}$} & \multirow{2}{*}{$\begin{array}{l}\text { Obstruction } \\
\text { Diameter } \\
(\mathrm{mm})\end{array}$} & \multirow{2}{*}{$\begin{array}{l}\text { Diameter } \\
\text { Stenosis } \\
(\%)\end{array}$} & \multicolumn{2}{|c|}{ Minimal Luminal Cross-Sectional Area } \\
\hline & & & & & $\begin{array}{l}\text { Edge Detection } \\
\left(\mathrm{mm}^{2}\right)\end{array}$ & $\begin{array}{l}\text { Densitometry } \\
\left(\mathrm{mm}^{2}\right)\end{array}$ \\
\hline 1 PreP & $70 \mathrm{M}$ & Conduit & 0.9 & 67 & 0.7 & 0.4 \\
\hline PostP & & & 2.2 & 24 & 3.8 & 4.7 \\
\hline PostS & & & 3.0 & 8 & 7.1 & 7.1 \\
\hline 2 PreP & $70 \mathrm{M}$ & Conduit & 1.2 & 55 & 1.2 & 0.4 \\
\hline PostP & & & 1.6 & 22 & 2.1 & 2.3 \\
\hline PostS & & & 2.3 & 10 & 4.1 & 2.3 \\
\hline 3 PreP & $52 \mathrm{M}$ & Right & 1.8 & 50 & 2.6 & 2.5 \\
\hline PostP & & & 2.1 & 46 & 3.5 & 5.3 \\
\hline PostS & & & 2.8 & 23 & 6.1 & 5.7 \\
\hline 4 PreP & $42 \mathrm{M}$ & LAD & 1.0 & 54 & 0.9 & 0.2 \\
\hline PostP & & & 1.6 & 31 & 2.1 & 1.9 \\
\hline PostS & & & 1.8 & 23 & 2.5 & 2.7 \\
\hline 5 PreP & $52 \mathrm{M}$ & LAD & 1.3 & 47 & 1.3 & 0.9 \\
\hline PostP & & & - & - & - & - \\
\hline PostS & & & 1.7 & 26 & 2.3 & 1.1 \\
\hline 6 PreP & $46 \mathrm{M}$ & Right & 1.0 & 67 & 0.7 & 0.3 \\
\hline PostP & & & 1.8 & 46 & 2.5 & 4.8 \\
\hline PostS & & & 2.5 & 28 & 4.9 & 5.7 \\
\hline 7 PreP & $69 M$ & $\angle A D$ & 1.1 & 62 & 0.9 & 1.0 \\
\hline PostP & & & 1.6 & 40 & 2.0 & 2.1 \\
\hline PostS & & & 2.1 & 28 & 3.5 & 3.0 \\
\hline 8 PreP & $64 \mathrm{~F}$ & LAD & 1.5 & 48 & 1.8 & 2.0 \\
\hline PostP & & & 2.0 & 26 & 3.3 & 3.0 \\
\hline Posts & & & 2.2 & 21 & 3.8 & 3.6 \\
\hline 9 PreP & $62 \mathrm{~F}$ & LAD & 0.7 & 73 & 0.4 & 0.4 \\
\hline PostP & & & - & - & - & - \\
\hline PostS & & & 2.2 & 16 & 3.8 & 4.0 \\
\hline 10 PreP & $51 \mathrm{M}$ & LAD & 1.7 & 27 & 2.2 & 1.4 \\
\hline PostP & & & 2.0 & 21 & 3.1 & 2.4 \\
\hline Posts & & & 2.3 & 15 & 4.1 & 3.6 \\
\hline 11 PreP & $41 \mathrm{M}$ & LAD & 0.6 & 81 & 0.3 & 0.3 \\
\hline PostP & & & 1.6 & 51 & 2.0 & 2.6 \\
\hline PostS & & & 2.5 & 30 & 4.9 & 3.8 \\
\hline 12 PreP & $51 \mathrm{~F}$ & LAD & 0.9 & 61 & 0.6 & 1.3 \\
\hline PostP & & & 2.1 & 25 & 3.5 & 4.3 \\
\hline PostS & & & 2.0 & 26 & 3.1 & 2.9 \\
\hline 13 PreP & $69 M$ & LAD & 1.3 & 59 & 1.3 & 1.2 \\
\hline PostP & & & 2.1 & 30 & 3.5 & 3.5 \\
\hline PostS & & & 2.4 & 20 & 4.5 & 4.5 \\
\hline 14 PreP & $51 \mathrm{~F}$ & Right & 1.0 & 60 & 0.8 & 0.3 \\
\hline PostP & & & 2.3 & 22 & 4.1 & 3.4 \\
\hline PostS & & & 2.4 & 21 & 4.5 & 5.0 \\
\hline 15 PreP & $54 M$ & LC & 1.2 & 52 & 1.1 & 1.1 \\
\hline PostP & & & 1.6 & 39 & 2.0 & 2.6 \\
\hline PostS & & & 2.3 & 26 & 4.1 & 4.1 \\
\hline 16 PreP & $55 \mathrm{~F}$ & LC & 0.8 & 61 & 0.5 & 0.2 \\
\hline PostP & & & 1.6 & 37 & 2.0 & 3.1 \\
\hline PostS & & & 1.9 & 25 & 2.8 & 2.6 \\
\hline 17 PreP & $54 \mathrm{~F}$ & LAD & 1.2 & 61 & 1.1 & 1.2 \\
\hline PostP & & & 1.7 & 35 & 2.3 & 4.5 \\
\hline PostS & & & 2.1 & 20 & 3.5 & 3.9 \\
\hline 18 PreP & $52 \mathrm{M}$ & LAD & 1.9 & 52 & 2.8 & 1.2 \\
\hline PostP & & & 2.7 & 39 & 5.7 & 7.1 \\
\hline PostS & & & 1.9 & 36 & 2.8 & 2.5 \\
\hline 19 PreP & $65 \mathrm{M}$ & LAD & 1.1 & 63 & 0.9 & 0.0 \\
\hline PostP & & & 2.3 & 17 & 4.1 & 1.6 \\
\hline PostS & & & 2.6 & 13 & 5.3 & 2.9 \\
\hline Mean \pm SD & & & & & & \\
\hline PreP & & & $\{1.2 \pm 0.4$ & * $\int 58 \pm 11$ & $1.2 \pm 0.7$ & $0.9 \pm 0.7$ \\
\hline PostP & & & $1.9 \pm 0.3$ & $\{32 \pm 10$ & $3.0 \pm 1.0$ & $3.5 \pm 1.5$ \\
\hline PostS & & & $\{2.3 \pm 0.3$ & $*\{22 \pm 7$ & $4.1 \pm 1.2$ & $3.9 \pm 1.4$ \\
\hline
\end{tabular}


placed to cover the entire dilated arterial segment. Medications at the time of the initial angiogram were intravenous heparin, acetylsalicylic acid, dipyridamole, nitrates and calcium antagonists. Coronary angiograms were performed before and after angioplasty, and after stent implantation.

Description of the stent: In this trial, the endovascular prosthesis, Wallstent ${ }^{\circledR}$, was provided by Medinvent SA, Lausanne. The method of implantation and description of this stent have been reported previously. ${ }^{13,14}$

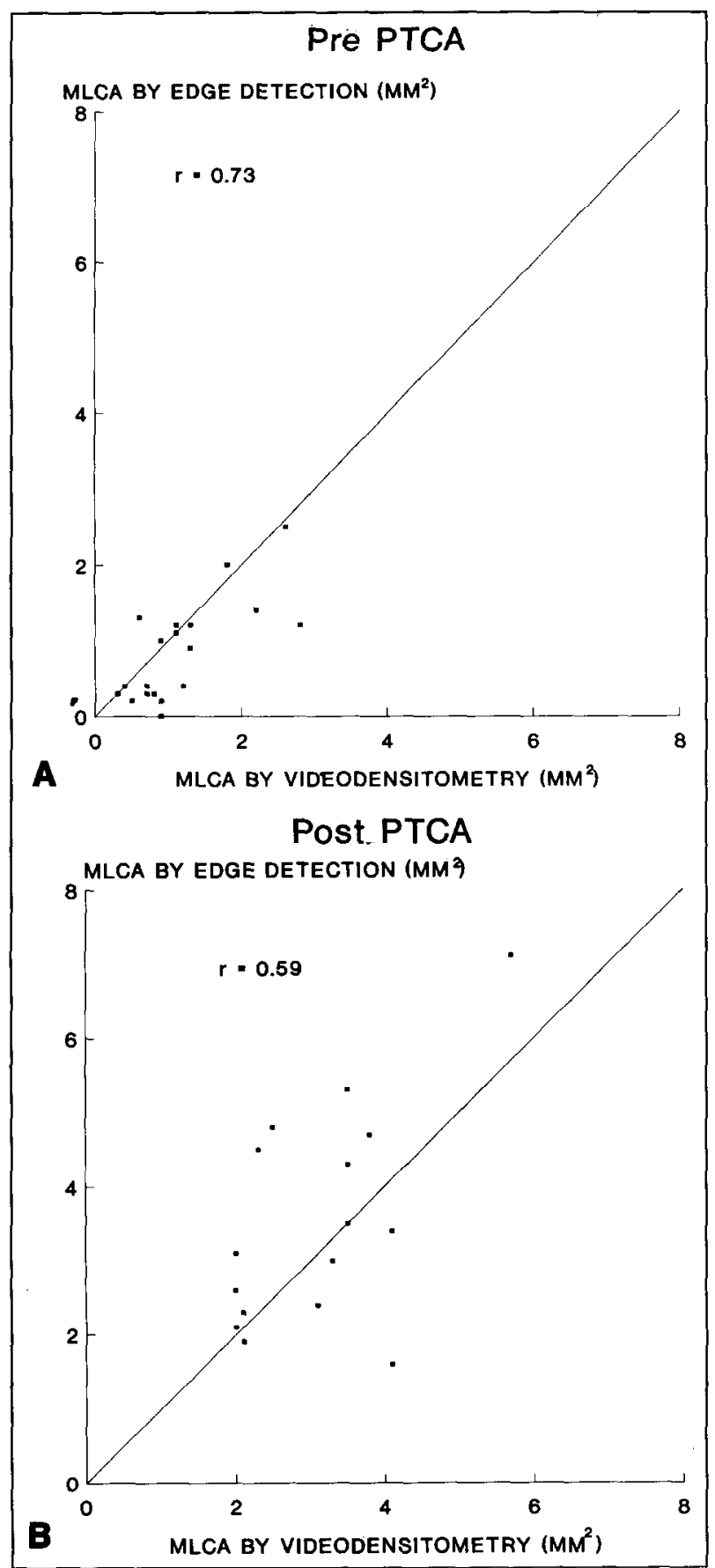

This stent is a self-expandable, stainless steel-woven mesh prosthesis that can be positioned in the coronary artery with the standard over-the-wire technique through an $8 \mathrm{Fr}$ or $9 \mathrm{Fr}$ guiding catheter. The device is constructed of sixteen 0.08 -mm-wide wire filaments. It is constrained in an elongated configuration on a 1.57mm-diameter delivery catheter, with the distal end covered by a removable plastic sleevc. As the sleeve is withdrawn, the constrained device returns to its original unconstrained larger diameter and becomes anchored against the vessel wall. Unconstrained stent diameter was selected to be $0.50 \mathrm{~mm}$ larger than the reference diameter of the stented vessel.

Quantitative coronary angiography: All cineangiograms were analyzed with the computer-assisted cardiovascular angiography analysis system, which has been discussed in detail previously. ${ }^{15-18}$ The important steps will be briefly described. Any area sized $6.9 \times 6.9 \mathrm{~mm}$ in a selected cineframe (overall dimensions $18 \times 24$ $\mathrm{mm}$ ) encompasing the desired arterial segment can be digitized by a high-resolution CCD-camera with a resolution of $512 \times 512$ pixels and 8 bits of gray level. Vessel contours are determined automatically based on the weighted sum of the first and second derivative functions applied to the digitized brightness information along scanlines perpendicular to the local centerline directions of an arterial segment. A computer-derived estimation of the original arterial dimension at the site of the obstruction is used to define the interpolated reference diameter. This technique is based on a computerderived estimation of the original diameter values over the analyzed region (assuming there was no disease

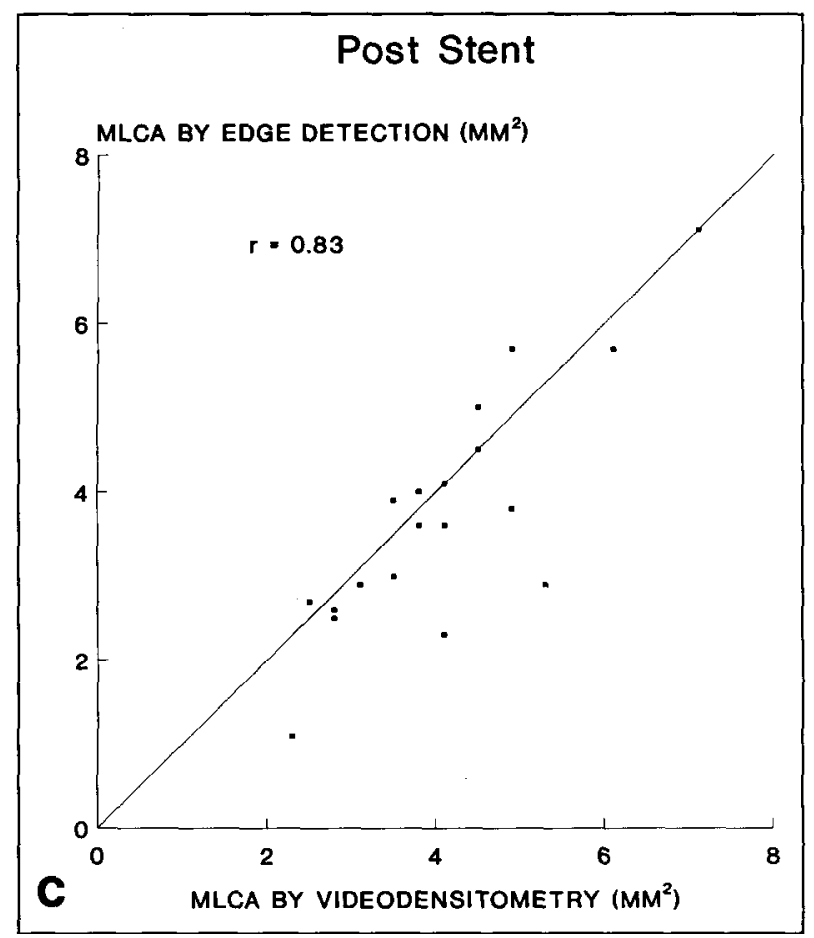

FIGURE 1. Individual data for minimal huminal cross-sectional area (MLCA) determined by edge detection and videodensitometry (A) before and (B) after percutaneous transluminal coronary angioplasty (PTCA) and (C) after sitenting. Diagonal line, equal measurements by the 2 methods. Vahues above line were higher by edge detection and below line higher by densitometry. 
present) according to the diameter function. The absolute diameter of the stenosis as well as the reference diameter are measured by the computer, which uses the known guiding catheter diameter as a calibration factor. All contour positions of the catheter and arterial segments are corrected for pincushion distortion. The minimal cross-sectional area of the narrowed segment and the interpolated percent area stenosis are then derived by assuming a circular model and comparing the observed stenosis dimensions to the reference values. The angiographic analysis was done using the view in which the arterial narrowing appeared the most severe and all interventions were performed.

Densitometric analysis: Densitometry is based on the approximate linear relation that exists between the optical density of a contrast-enhanced lumen and the absolute dimensions of the arterial segment. Constitution of the relation between the path length of the $x$ rays through the artery and the brightness values requires a detailed analysis of the complete $\mathrm{x}$-ray/cine/ video chain, including the film development process.

For the first part of the chain, from the x-ray tube to the output of the image intensifier, we use Lambert Beer's law for the $\mathrm{x}$-ray absorption and apply certain models for the $x$-ray source and the image intensifier. From the output of the image intensifier up to the brightness values in the digital image, we use a simple linear transfer function. Details of this technique have been described elsewhere. ${ }^{5,15-18}$

The cross-sectional area of a vessel is then obtained as follows: When selecting a cineframe for the densitometric analysis, we ensure that the main axis of the segment is reasonably perpendicular to the incoming $\mathrm{x}$-rays (i.e., a nonforeshortening view is chosen). Contours of the artery are detected by automated contour detection as previously described. From the measured diameters along the analyzed segment, the diameter data described above are derived. On each scanline perpendicular to the local centerline direction of the vessel, a profile of brightness values is measured. This profile is transformed into an absorption profile by means of a simple logarithmic transfer function. The background contribution is estimated by computing the linear regression line through the background points directly left and right of the detected contours. Subtraction of this background portion from the absorption profile within the arterial contours yields the net cross-sectional absorption profile. Integration of this function gives a measure for the cross-sectional area at the particular scanline. By repeating this procedure for all scanlines, the cross-sectional area function is obtained. A reference densitometric area is obtained following the same principles as previously described for the diameter measurements. It is clear that homogeneous mixing of the contrast agent and the blood must be assumed for the measurement to be correct. The complete procedure has been evaluated with the cinefilms of Plexiglas ${ }^{\star}$ models of coronary obstructions. ${ }^{16}$

To determine whether the physical properties of the stent itself interfere with the densitometric assessment, Wallstents ${ }^{\circ}$ were placed inside known stenoses within perspex models and the minimal luminal cross-sectional area was calculated by densitometry. These cylindrical models, $5 \mathrm{~mm}$ in diameter at the ends and tapering to either 2 or $3 \mathrm{~mm}$ in the center, were filled with iopamidol (50 or $100 \%$ concentration) and angiographic studies were done at $75 \mathrm{kV}$ to approximate the clinical setting. The calculated values for minimal luminal crosssectional area were 0 to $12 \%$ higher in the stented models, compared with identical phantoms that did not contain stents.

Statistical analysis: The individual data for minimal luminal diameter and minimal luminal cross-sectional area by edge detection and densitometry, respectively, were used to calculate the mean value \pm standard deviation (Table I). Analysis of variance was performed to compare the mean minimal luminal diameter before and after PTCA and after stenting and, if significant differences were found, 2-tailed $t$ tests were applied. A value $<0.05$ was considered statistically significant.

To measure the strength of the relation between the 2 methods of analysis-edge detection and densitometry-in determining minimal luminal cross-sectional area, the product-moment correlation coefficient (r) and its $95 \%$ confidence intervals were calculated at the 3 distinct times of study. The agreement between the 2 measures was assessed by determining the mean and the standard deviation of the between-method difference, as

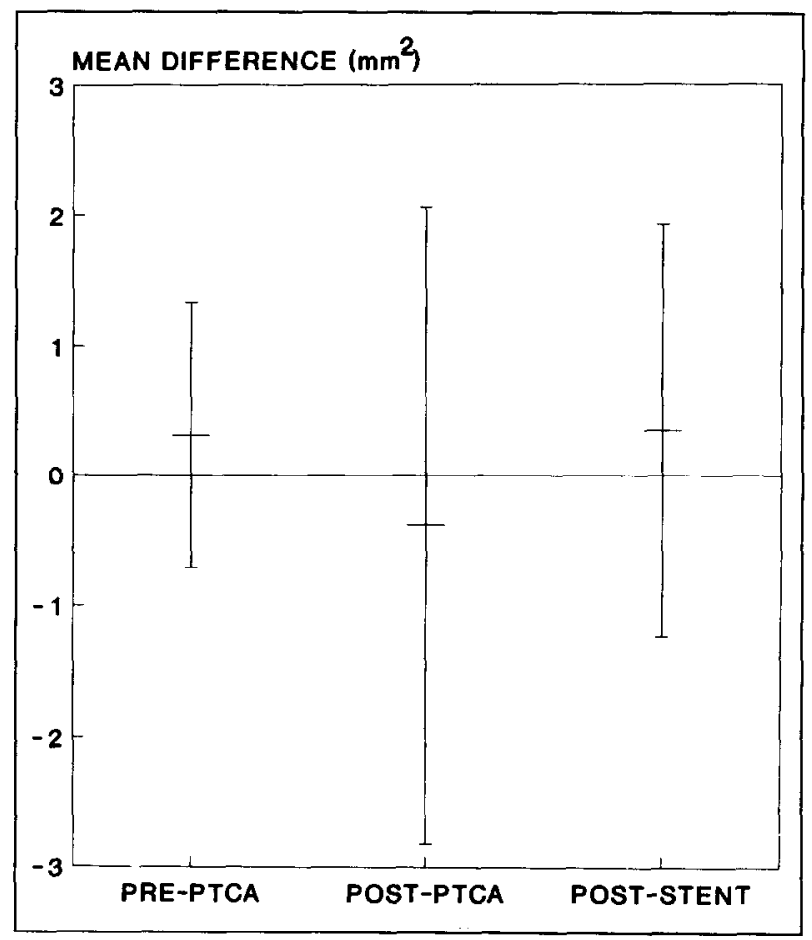

FIGURE 2. Mean difference between edge detection and densitometry and $95 \%$ confidence intervals before and after percutaneous transhuminal coronary angioplasty (PTCA) and after stenting. Mean differences were slightly positive $(0.31$, $0.35 \mathrm{~mm}^{2}$ ) before PTCA and after stenting, respectively, and silighty negative $\left(-0.38 \mathrm{~mm}^{2}\right)$ after PTCA. The wldest $95 \%$ confidence interval was in the analysis after PTCA, indicating the poorest association between the 2 methods, compared with the analysis before PTCA and after stenting. 
suggested by Bland and Altman. ${ }^{19}$ At each interval this was done by computing the sum of the individual differences between the 2 methods to determine the mean difference and the standard deviation.

\section{RESULTS}

The individual data obtained by contour detection and videodensitometric analysis are listed in Table $I$. There was an overall significant increase in the minimal luminal diameter and a decrease in percent diameter stenosis after angioplasty $(1.2 \pm 0.3$ to $1.9 \pm 0.3 \mathrm{~mm}$ and $58 \pm 11$ to $32 \pm 10 \%$, respectively) and after stenting $(2.3 \pm 0.3 \mathrm{~mm}, 22 \pm 7 \%)$.

The correlation between edge detection and densitometry in the assessment of minimal luminal cross-sectional area before and after PTCA, and after stenting is
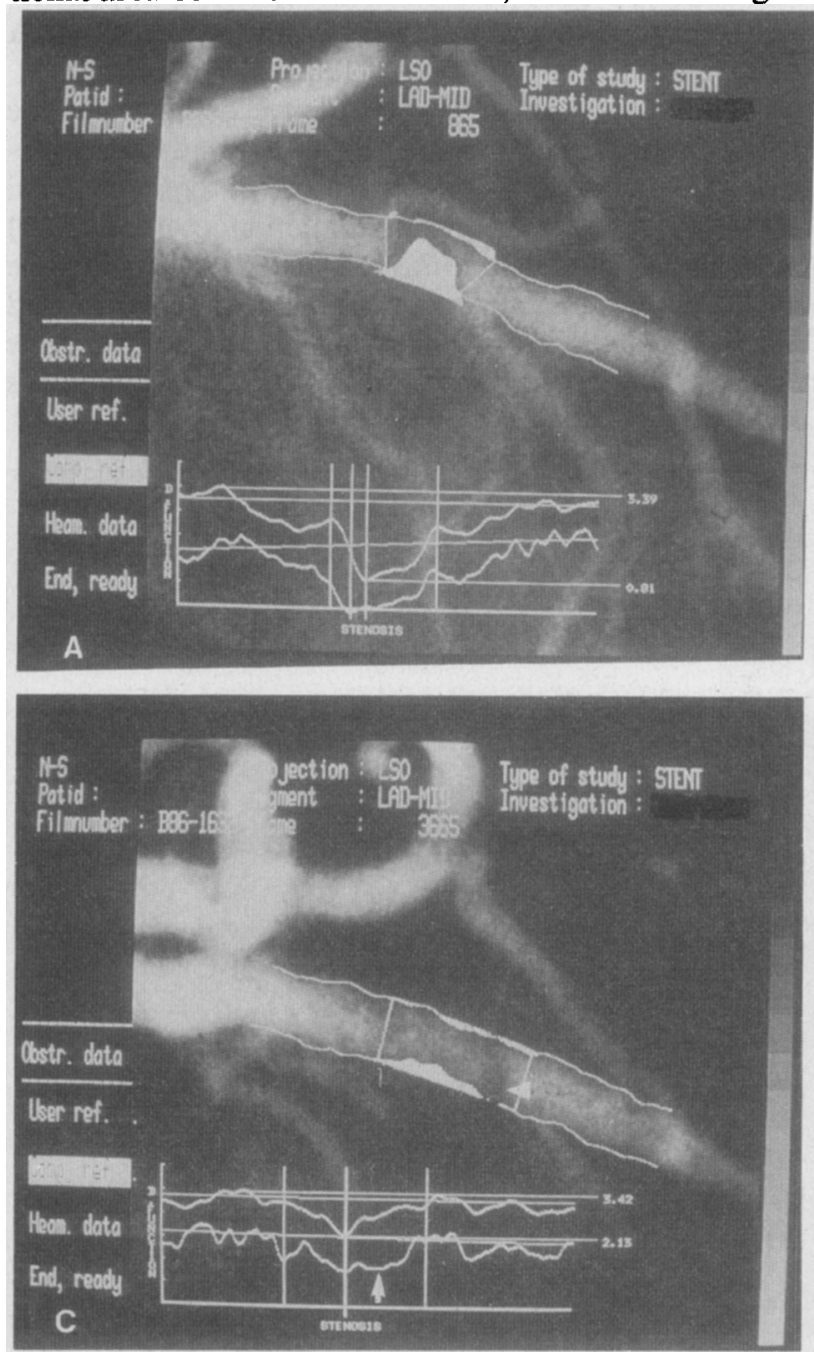

shown in Figures 1A, 1B and 1C, respectively. Before angioplasty, correlation coefficient was 0.73 (95\% confidence interval, 0.41 to 0.89 ), indicating a reasonably linear relation. However, this deteriorated after PTCA, resulting in a correlation coefficient of 0.59 (95\% confidence interval, 0.15 to 0.83 ). However, linearity was significantly improved with the implantation of a coronary stent (correlation coefficient, $0.83 ; 95 \%$ confidence interval, 0.61 to 0.93 ).

The agreement between the 2 measures is illustrated in Figure 2. The determination of minimal luminal cross-sectional area was slightly higher by edge detection than by videodensitometry in the before PTCA and after stenting analyses (mean differences, 0.31 and 0.35 $\mathrm{mm}^{2}$, respectively) and slightly lower after PTCA (mean difference, $-0.38 \mathrm{~mm}^{2}$ ). The variability as deter-
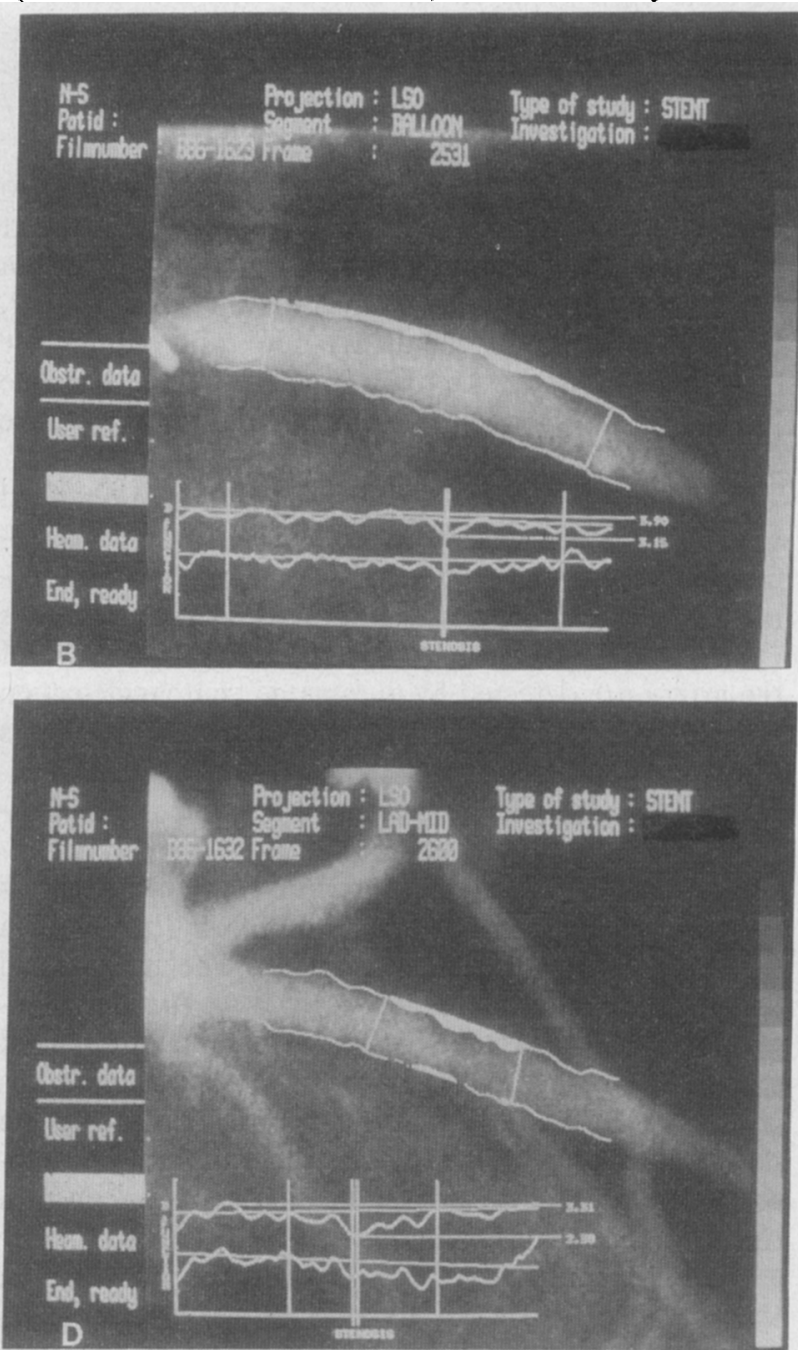

FIGURE 3. Edge contour and densitometric analysis of an obstruction in the left anterior descending (LAD) artery before percutaneous transhuminal coronary angioplasty [PTCA] (A), during balloon inflation (B), after PTCA (C) and after stenting (D). Graphs show the diagnostic diameter function (upper curve) and the densitometric area function (lower curve). Lower horizontal line $(0.81 \mathrm{~mm}$ in frame A) is the minimal huminal diameter. Outside vertical lines on the graph and the 2 vertical lines on the angiogram are lesion boundaries. Inner vertical lines on graph are the site in the lesion of minimal luminal diameter. In the angiogram before PTCA (A), contour and densitometry curves are parallel. There was a marked improvement in the minimal huminal diameter of the lesion during balloon imfiation (B). After PTCA (C), contour and densitometry curves diverge (arrow) at the site of an intraluminal haxiness (arrowhead). In the diameter function, there is a descending limb of the curve that reaches a nadir and immediately is followed by an ascending limb. However, the densitometry curve shows a descending limb followed by a plateau. After stenting (D), the relation between the 2 curves is restored. 
mined by the standard deviation of the differences between the 2 measurements was highest in the analysis after PTCA $\left(1.22 \mathrm{~mm}^{2}\right)$, compared to before PTCA and after stenting ( 0.51 and $0.79 \mathrm{~mm}^{2}$, respectively). An individual example is shown in Figure 3.

\section{DISCuSSION}

The ideal method by which to perform angiographic analysis after coronary interventions, including balloon angioplasty and stenting, remains debatable. Although densitometry is independent of geometric shape, its application is limited in the presence of branch vessels that may cause errors in the background correction technique and in situations where the $\mathrm{x}$-ray beam is not perpendicular to the long axis of the vessel. Additional clinical factors that contribute to the inaccuracy of densitometry include $x$-ray scatter, light scatter within the image intensifier (veiling glare) and beam hardening of the polychromatic $x$-ray flux because of iodine and tissue thickness. Discrepancies between edge detection and densitometry are most likely to occur when the shape of the vessel wall at the level of the lesion deviates furthest from a circular configuration, because this is a basic assumption in the calculation of minimal luminal crosssectional area by edge detection.

This study illustrates several important points. First, we have shown that a relation exists between the 2 measurements at all stages of the procedure, but the

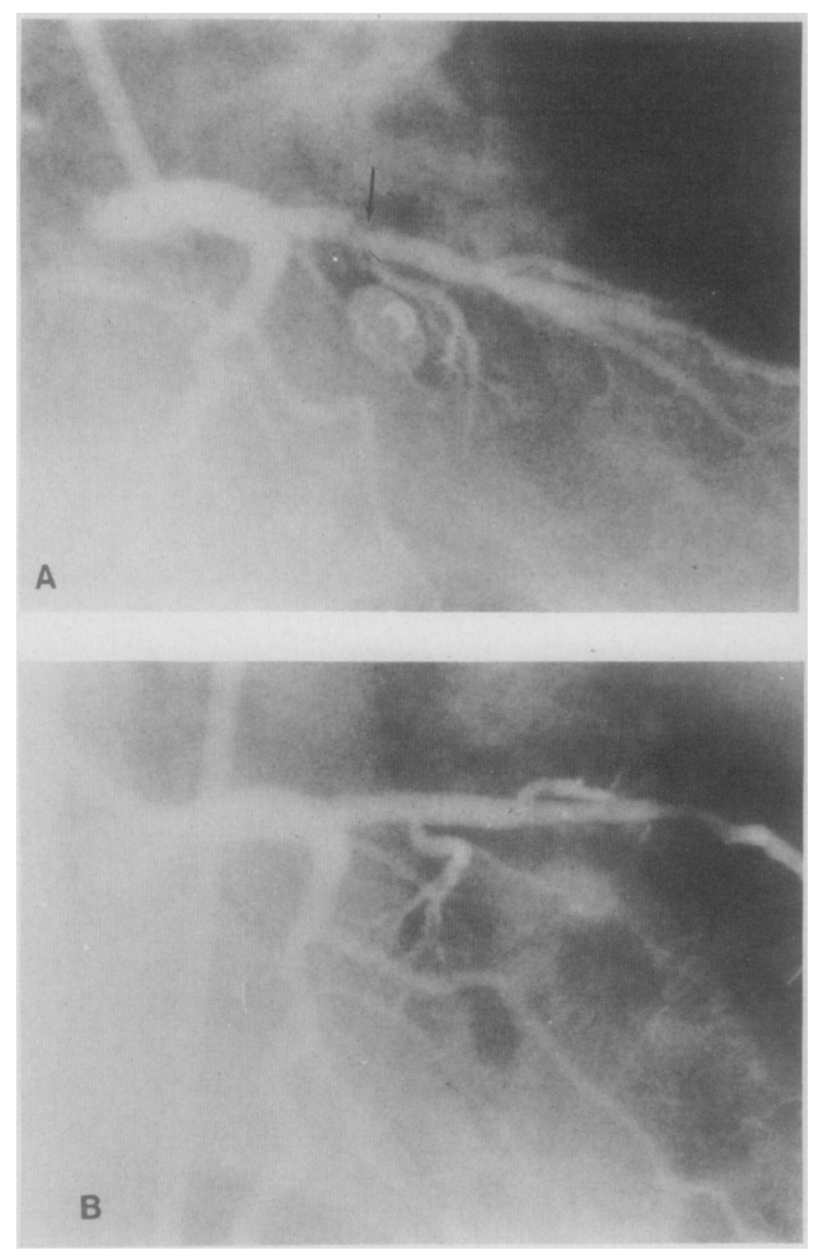

strength of this relation, based on the magnitude of the correlation coefficient, deteriorates after PTCA and then improves after stenting. Furthermore, although mean differences between the 2 methods were small in all analyses, the greatest variability and thus the poorest agreement occurred in the analysis after PTCA. The before and after PTCA results are in accordance with carlier observations by our group. ${ }^{5}$ At that time we suggested that measurement of cross-sectional area from a single view is inaccurate. Subsequent studies by Tobis et al $^{11}$ comparing edge detection in 2 orthogonal views and by Lesperance et $\mathrm{al}^{12}$ comparing single versus the mean of multiple views have shown similar and high correlations both before and after PTCA. However, use of the correlation coefficient alone is not an adequate measure of agreement between 2 measurement techniques for several statistical reasons. ${ }^{19,20}$ Determination of the mean and standard deviation of the between-method differences should be included in the analysis.

Two factors probably contributed to the improved agreement after stent implantation. Vessel contours appeared more regular and smooth and in some cases intimal flaps appeared to be tacked back by the scaffolding property of this stent. However, even more important, the self-expanding property of this stent not only additionally dilated the vessel, but also probably remodeled the stented segment into a more circular geometry. This has previously been shown in vivo after the implantation of coronary stents in animals and in some human coronary vessels (Figure 4, A, B and C).

A potential limitation of densitometry in the analysis after stenting may be a spuriously high determination of minimal luminal cross-sectional area (up to $12 \%$ in the

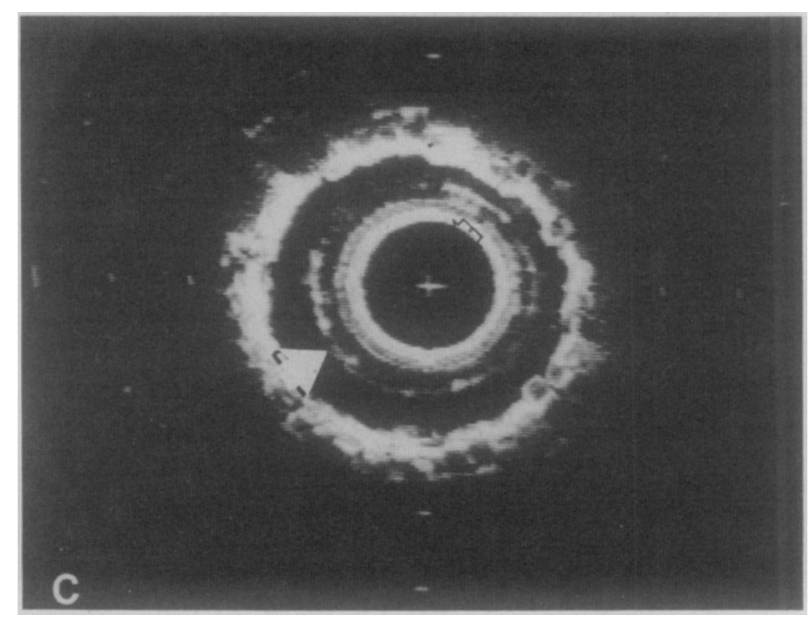

FIGURE 4. A, angiogram of left anterior descending artery stenosis after dissection (arrow) during percutaneous transhminal coronary angioplasty. $B$, angiographic appearance of left anterior descending artory losion aftor stomting showing smooth contour. $C$, in vitro intravascular ultrasound examination of this vessel 24 hours after stenting (patient died from intracerebral hemorshage 12 hours after stenting). Tho inner circle is due to intravascular probe. The outer echodense pattern is dure to stent wires (Jarge arrow). The humen (small open arrow) is the echo-free space inside the stent. The stent effectively tacked back the dissection and restored the circular configuration of the vessel (courtesy of Dr. Bernardino Tucillo). 
phantom studies) because of interference from the stent itself. This is probably related to the composition of the stent, surface area or additional factors, such as increased scatter in the stenotic section because of the stent. Although the mean differences in minimal luminal cross-sectional area between the edge detection and densitometry were small, the negative mean difference in the analysis after stenting (i.e., larger values by densitometry) in contrast to the positive mean difference after PTCA can be partly explained by this contribution of the stent to the densitometrically determined values. The effect of other currently available stents should be separately assessed and considered in angiographic analyses using densitometry.

Acknowledgment: We gratefully acknowledge the statistical assistance of Jan Tijssen, PhD.

\section{REFERENCES}

1. Sigwart U, Puel J, Mirkowitch V, Joffre F, Kappenberger L. Intravascular stents to prevent occlusion and restenosis after transluminal angioplasty. $N$ Engl $J$ Med 1987;316:701-706.

2. De Rouen TA, Murray JA, Owen W. Variability in the analysis of coronary arteriograms. Circulation 1977;55:324-328.

3. Trask N, Califf RM, Conley MJ, Kong Y, Peter R, Lee KL, Hackel DB, Wagner GS. Accuracy and interobserver variability of coronary cineangiography: a comparison with postmortem evaluation. $J$ Am Coll Cardiol 1984;3:1145-1154. 4. Holder DA, Johnson AL, Stolberg HO, Campbell M, Gustensen J, Joyal M, Roberts R, Biagioni EM, Vaughan W, Romeo M. Inability of caliper measurements to enhance observer agreement in the interpretation of coronary cineangiograms. Can I Cardiol 1985;1:24-29.

5. Serruys PW, Reiber JHC, Wijns W, van den Brand M, Kooijman CJ, ten Katen HJ, Hugenholtz PG. Assessment of percutaneous transluminal coronary angioplasty by quantitative coronary angiography: diameter versus densitometric area measurements. Am J Cardiol 1984;54:482-488.

6. Smalling R. Can the immediate efficacy of coronary angioplasty be adequately assessed? J Am Coll Cardiol 1987;10:261-263.
7. Zijlstra F, van Ommeren $J$, Reiber JHC, Serruys PW. Does quantitative assessment of coronary artery dimensions predict the physiological significance of a coronary stenosis? Circulation 1987;75:1154-1161

8. Harrison DG, White CW, I Iiratzka LF, Doty DB, Barnes DH, Eastham CL, Marcus ML. The value of lesion cross-sectional area determined by quantitative coronary angiography in assessing the physiologic significance of proximal left anterior descending arterial stenoses. Circulation 1984;69:1111-1119

9. Vlodaver Z, Edwards JE. Pathology of coronary atherosclerosis. Prog Cardiovasc Dis 1971;14:156-174.

10. Saner HE, Gobel FL, Salomonowitz E, Erlien DA, Edwards JE. The diseasefree wall in coronary atherosclerosis: its relation to degree of obstruction. $J \mathrm{Am}$ Coll Cardiol 1985;6:1096-1099.

11. Tobis J, Nalcioglu O, Johnston WD, Qu L, Reese T, Sato D, Roeck W, Montelli S, Henry WL. Videodensitometric determination of minimum coronary artery luminal diameter before and after angioplasty. $A m J$ Cardiol 1987;59: 38-44.

12. Lesperance J, Hudon $G$, White $C W$, Laurier J, Waters D. Comparison by quantitative angiographic assessment of coronary stenoses of one view showing the severest narrowing to two orthogonal views. Am J Cardiol 1989:64:462-465. 13. Puel J, Julliere Y, Bertrand ME, Rickards AF, Sigwart U, Serruys PW. Early and late assessment in stenosis geometry after coronary arterial stenting. $A m J$ Cardiol 1988;61:546-553.

14. Serruys PW, Julliere $Y$, Bertrand ME, Puel J, Rickards AF, Sigwart U, Additional improvement of stenosis geometry in human coronary arteries by stenting after balloon dilatation: a quantitative angiographic study. Am J Cardiol 1988:61:71G-76G.

15. Reiber JHC, Kooijman CJ, Slager CJ, Gerbrands JJ, Schuurbiers JHC, den Boer A, Wijns W, Serruys PW, Hugenholtz PG. Coronary artery dimensions from cineangiograms: methodology and validation of a computer-assisted analysis procedure. IEEE Trans Med Imag 1984:MI3:131-141.

16. Reiber JHC, Serruys PW, Slager CJ. Quantitative Coronary and Left Ventricular Cineangiography. Methodology and Clinical Application. Dordrecht, Martinus Nijhoff Publishers, 1986.

17. Reiber JHC, Slager CJ, Schuurbiers JCH, den Boer A, Gerbrands JJ, Troost GJ, Scholts B, Kooijman CJ, Serruys PW. Transfer functions of the X-ray cine video chain applied to digital processing of coronary cineangiograms. In: Heintzen PH, Brennocke R, eds. Digital Imaging in Cardiovascular Radiology. StuttgartNew York: George Thieme Verlag, 1983:89-104.

18. Reiber JHC, Serruys PW, Kooijman CJ, Wijns W, Slager CJ, Gerbrands JJ, Schuurbiers ICH, den Boer A, Hugenholtz. PG. Assessment of short-, mediumand long-term variations in arterial dimensions from computer-assisted quantification of coronary cineangiograms. Circulation 1985;71:280-288.

19. Bland JM, Altman DG. Statistical methods for assessing agreement between two methods of clinical measurement. Lancet 1986;307-310.

20. Evans SJW, Mills P, Dawson J. The end of the p value? Br Heart $J$ 1988;60:177-180. 